DOI 10.30612/re-ufgd.v7i13.10863

\title{
DEFUMAÇÃO DA TRAÍRA (Hoplias malabaricus) COMO MÉTODO ALTERNATIVO DE CONSERVAÇÃO
}

\author{
TRAIRA (Hoplias malabaricus) SMOKING AS AN ALTERNATIVE METHOD TO \\ CONSERVATION
}

Wesley Clovis Barbieri Mendonça ${ }^{1}$
Arypes Scuteri Marcondes $^{1}$
Jean Carlos de Souza Melo ${ }^{1}$
Henrique Momo Ziemniczak ${ }^{2}$
Rebeca Maria Sousa ${ }^{3}$
Claucia Aparecida Honorato ${ }^{4}$

Recebido em 20/12/2019

Aceito em 30/04/2020

Resumo: Objetivou-se com este trabalho demonstrar o processo alternativo de conservação por meio da defumação, de peixes da espécie traíra (Hoplias malabaricus). O público alvo desta ação foram os produtores rurais, universitários, professores, técnicos agrícolas e a comunidade geral. Foram usados espécimes de traíra proveniente de pesca amadora, subdividido em três classes de peso (pequeno 453g, médio $689 \mathrm{~g}$, grande $781 \mathrm{~g}$ ) e com filés utilizando diferentes processamentos de corte. A defumação foi realizada com o auxílio de um defumador artesanal em aço inox, com geração de fumaça externa à câmara de defumação. Antes e após a defumação os peixes foram submetidos à análise de coloração utilizando-se colorímetro (Konica Minolta®) e pH. Após o processo, foi realizado o teste de aceitação do produto pelo público que realizou o treinamento da técnica de defumação. O tamanho e o processamento do peixe influenciam o tempo de defumação. Para os produtores a diversificação do processamento de peixe pode ser um fator positivo para o consumo interno e uma possibilidade de comercialização do produto ofertado. Durante o desenvolvimento destas ações e treinamento técnico ocorreu também uma integração acadêmica com articulação entre extensão e pesquisa, onde às analises foram fundamentais para garantir a viabilidade da técnica de defumação. A defumação foi benéfica e bem sucedida para a carne de traíra uma vez que houve aumento da coloração avermelhada e também aumento da coloração amarela. Fatores estes que caracterizam o produto defumado. Conclui-se que a defumação é uma técnica que aumenta a viabilidade, agregando valor do pescado no comércio.

\footnotetext{
${ }^{1}$ Graduando em Engenharia de Aquicultura, na Universidade Federal da Grande Dourados.

2 Pós-Graduando em Zootecnia, na Universidade Federal da Grande Dourados.

${ }^{3}$ Mestre em Zootecnia, na Universidade Federal da Grande Dourados.

${ }^{4}$ Docente da Faculdade de Ciências Agrárias, na Universidade Federal da Grande Dourados.
} 
Palavras-chave: controle de qualidade, Hoplias malabaricus, peixes para consumo

Abstract: The objective of this work was to demonstrate the process of fish conservation through smoking. The target audience for this action were farmers, university students, teachers, agricultural technicians and the general community. We used specimens of traíra from amateur fishing, subdivided into three weight classes (small 453g, medium $689 \mathrm{~g}$, large 781g) and with fillets using different cutting processes. The smoking was carried out in a handmade stainless steel smoker, with smoke generated outside the smoking chamber. Before and after smoking the fish were subjected to color analysis using colorimeter (Konica Minolta ${ }^{\circledR}$ ) and $\mathrm{pH}$. After the process, the product acceptance test was performed by the public who performed the smoking technique training. Fish size and processing influence smoking time. For producers the diversification of fish processing can be a positive factor for domestic consumption and a possibility of commercialization of the offered product. During the development of these actions and technical training there was also an academic integration with articulation between extension and research, where the analyzes were fundamental to ensure the viability of the smoking technique. Smoking was beneficial and successful for the meat of traira as there was an increase in reddish color and also increases in yellow coloration. These factors characterize the smoked product. It is concluded that smoking is a technique that increases viability, adding value to fish in trade.

Keywords: Flavor, trade, Hoplias malabaricus, quality

\section{INTRODUÇÃO}

Entre os peixes de água doce, a Hoplias malabaricus, popularmente conhecida como traíra é uma espécie com ampla distribuição geográfica na América do Sul, habitando a maioria das bacias hidrográficas (VOLCAN et al., 2012). É uma espécie neotropical pertencente à família Erythrinidae, sendo frequentemente utilizada para consumo humano, apresentando características produtivas desejáveis como adaptabilidade, alta taxa de proliferação e crescimento (LOZANO et al., 2014). Além disso, a traíra apresenta bom rendimento de carcaça e alta qualidade de carne, características que poderiam classificá-la como uma espécie alvo para a criação em cativeiro (GUIMARÃES et al., 2017; REIS et al., 2017).

Para a nutrição humana o peixe é uma importante fonte de lipídios ricos em ácidos graxos e proteínas de alto valor biológico. No entanto, como todo pescado, é um alimento perecível e altamente suscetível à deterioração devido à sua composição química, desta forma requer grande cuidados desde o processo de captura e armazenamento até a sua comercialização (PAZIANOTO et al., 2016; PIRES et al., 2017; VIDAL et al., 2017).

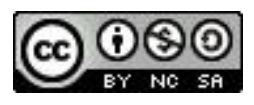


Sem a aplicação de qualquer medida de conservação ou processamento, o sabor e textura de produtos aquícolas muda rapidamente durante o armazenamento após captura (SOUZA et al., 2004). Para estimular o consumo de peixe visa-se buscar melhores formas de apresentação do produto. Nesse contexto, a defumação é um método tradicional que tem como finalidade a conservação do alimento proporcionando sabor e cor, deposição de substâncias antioxidantes, além de reduzir concentração de compostos indesejáveis (ADEYEYE;OYEWOLE, 2016). Assim, a defumação aperfeiçoa as características organolépticas como aroma, e textura, sendo um processo que apresenta ação bactericida e bacteriostática, aumentando a vida de prateleira (SOUZA et al., 2005; FRANCO et al. 2010; GEORGE et al., 2014).

Considerando a importância do emprego de ferramentas e processos tecnológicos que possam conter os diversos fatores de deterioração do pescado, buscou-se avaliar o efeito da defumação em traíras obtidas em estabelecimentos de pesca amadora, para analisar características físico-químicas e organolépticas (aparência, aroma, cor, sabor, textura, teor de sal e aceitação) obtidas após o processo.

\section{METODOLOGIA}

O presente trabalho foi desenvolvido pela Universidade Federal da Grande Dourados (UFGD) na comunidade produtora de peixes Assentamento Itamaraty e também com pescadores artesanais.

Foram realizados quatro encontros formados por docentes, discentes e bolsistas de extensão (UFGD), ações estas orientadas sobre os procedimentos e técnicas de higiene sanitária para os procedimentos a serem adotados para manutenção e qualidade do produto para alimentação humana.

As ações de Extensão Rural de cunho social e treinamento realizadas no assentamento Itamaraty, tiveram como intenção a interação entre o ensino a pesquisa e a extensão de forma harmônica. Onde foram realizadas reuniões iniciais e decidido por todos que no primeiro momento seriam utilizados exemplares de traíra, uma vez que este é um peixe que a comunidade constantemente adquire na pesca. Foram utilizados em cada encontro 10 exemplares de traíra (Hoplias malabaricus). Os exemplares utilizados para a defumação foram subdivididos em três classes de peso, devido à grande heterogeneidade apresentada. Sendo divididos como: pequeno 453g; médio 689g e grande 781g (Figura 1). Os peixes foram lavados com água corrente, e submetidos à análise visual para controle de qualidade. 


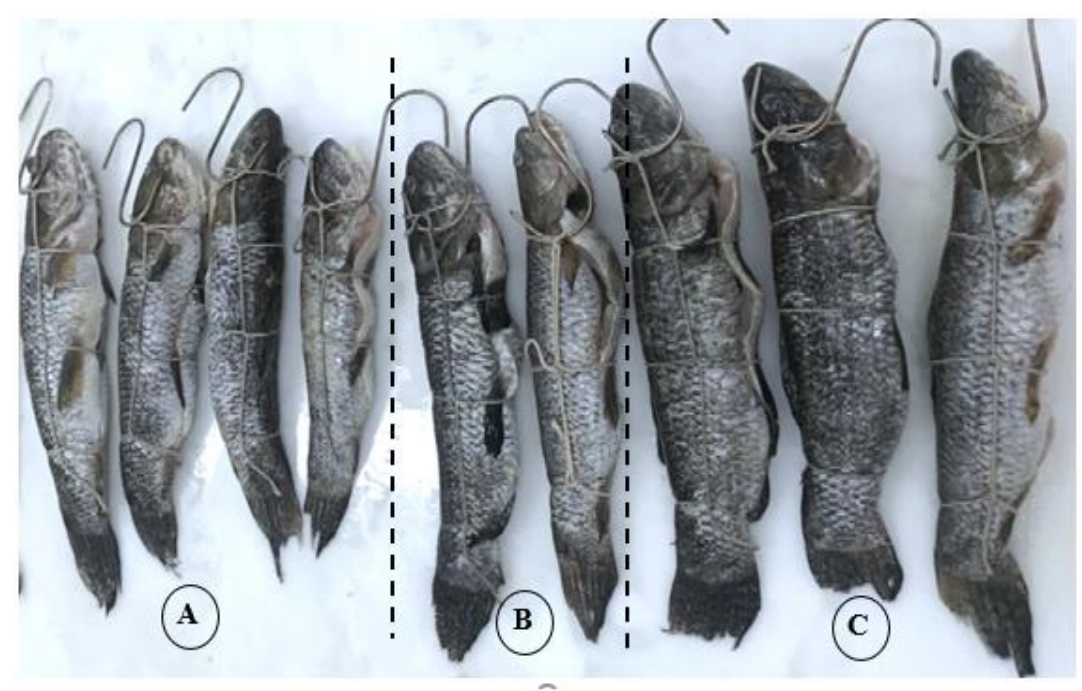

Figura 1. Exemplares de traíra com diferentes tamanhos e pesos. A, peixe pequeno; $\mathrm{B}$, peixe médio; $\mathrm{C}$, peixe grande.

Procedeu-se três formas de preparo: Peixe inteiro, peixe filetado e peixe filetado e recortado. Os peixes foram submetidos ao processo de salmoura com $\mathrm{NaCl} 20 \%$ por 30 minutos e em seguida foram lavados e pendurados por 45 minutos para drenagem e redução da água superficial, sendo adaptada a metodologia feita por Morais et al., (1996).

Os peixes foram colocados dentro da câmara de defumação, para secagem parcial a uma temperatura de $65^{\circ} \mathrm{C}$, durante 60 minutos. Decorrido esse período, foi iniciada a adição de fumaça. Foi utilizado um defumador artesanal de aço inox, com geração de fumaça externa à câmara de defumação. O combustível utilizado para produzir à fumaça foi à serragem de eucalipto rosa (Eucalyptus Globulus Labill) (ASSIS et al., 2009). A temperatura da defumação iniciou com $60^{\circ} \mathrm{C}$ até atingir $80^{\circ} \mathrm{C}$ na última hora de defumação, com acréscimo de $10^{\circ} \mathrm{C}$ a cada hora, totalizando 4 horas de exposição à fumaça para os peixes pequenos e 6 horas para os peixes grandes.

Para determinação do rendimento, os peixes foram pesados antes e após o processo de defumação. Todos os dados de rendimento foram calculados em relação ao peso total do espécime [(Peso do peixe defumado/peso peixe inteiro) $\mathrm{x} 100]$.

\section{Análise da composição físico-química}

A análise da coloração foi realizada conforme descrito por Houben et al., (2000) citado por Mendes et al. (2012), utilizando-se colorímetro (Konica Minolta®), avaliandose a luminosidade $\left(\mathrm{L}^{*}\right)(0=$ preto; $100=$ branco $)$, a intensidade da cor vermelha $\left(\mathrm{a}^{*}\right)$ e a 
intensidade da cor amarela $\left(b^{*}\right)$. A calibração do aparelho foi realizada conforme as instruções do fabricante. Para a análise do $\mathrm{pH}$ foi utilizado o parâmetro digital.

\section{RESULTADOS E DISCUSSÃO}

Durante as práticas realizadas na comunidade produtora de peixes Assentamento Itamaraty, foi possível observar uma interação e interesse dos produtores pela técnica de defumação. Deste modo, a atividade de extensão universitária teve a possibilidade de atender uma demanda da sociedade que precisa de informações e alternativas para agregar valor, e aumentar o tempo de prateleira e conservação do pescado.

Realizou-se a preparação de filés de traíra como alternativa de processamento (Figura 2A). Esta espécie de pescado apresenta muitos espinhos intramusculares por este motivo procedeu-se o recorte do filé (Figura 2B).
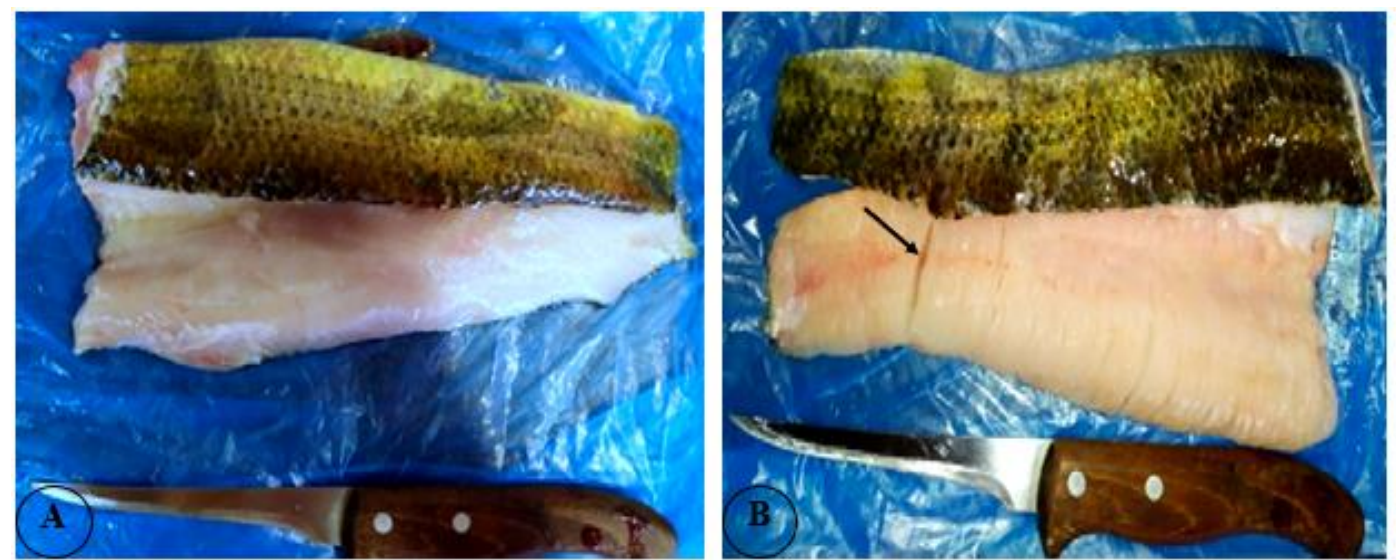

Figura 2. Corte dos filés de traíra usados para defumação. A, carcaça após a retirada da coluna vertebral juntamente com as costelas; B, notar a seta indicando cortes transversais com a finalidade de cortas as espinhas (que não sei o nome)

Verificou-se diferença no tamanho do peixe após a defumação, sendo os s peixes pequenos e os filés ficaram no padrão de produtos defumados com 4 horas de exposição à fumaça, adquirindo coloração e consistência típica. Souza et al. (2004) relatam que ocorre perda de peso durante os processos de defumação, explicando o motivo de peixes menores e filés terem adquiridos primeiros as características de peixe defumado. Os peixes classificados como médios e grandes precisaram retornar a câmera de defumação para mais 2 horas de defumação (Figura 3). A perda de umidade é um processo desejável na defumação de pescado, a qual auxilia em uma maior conservação da carcaça após o 
processo de defumação, sendo indicado teores abaixo de 65\% de umidade (MORAIS et al., 1996; GONÇALVES e CEZARINI, 2008).

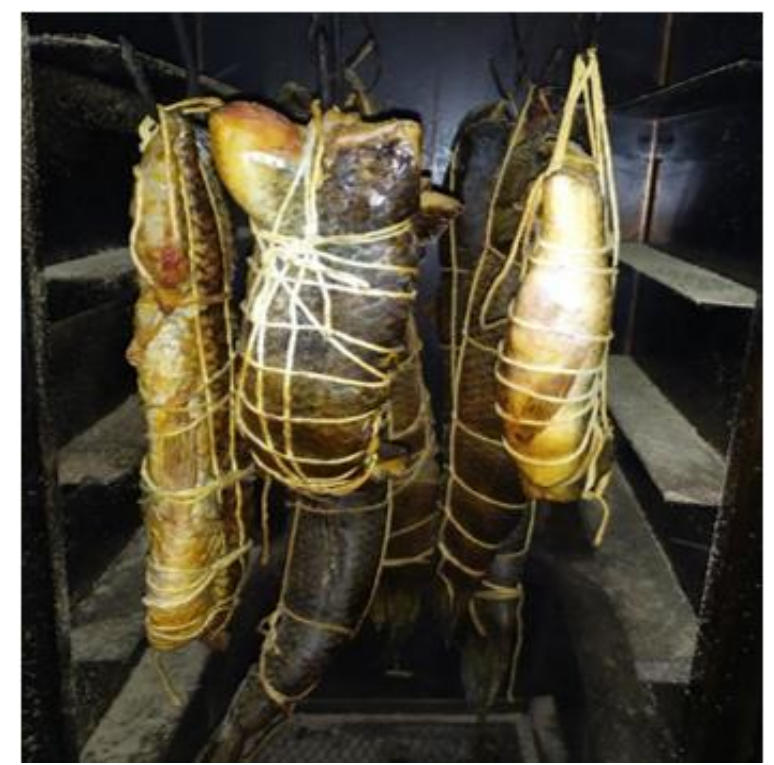

Figura 3. Peixes grande submetidos ao processo de defumação por mais de 4 horas

A análise de coloração demonstrou que a luminosidade do pescado não foi afetada pelo processo de defumação (Figura 4A). Foi observado um aumento da coloração avermelhada e amarela. Fatores estes que caracterizam o produto defumado (MORAIS et al., 1996). Assim, o filé de traíra apresentou uma melhor aparência no tocante a coloração, quando comparado ao peixe inteiro. (Figura 4B).
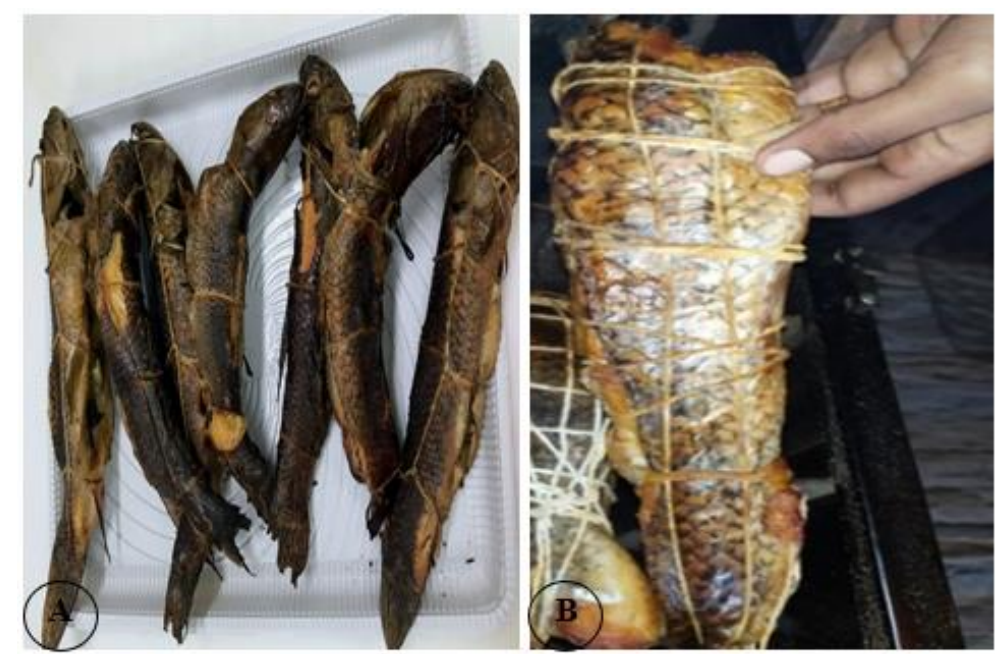

Figura 4. A, peixe inteiro defumado; B, filé de peixe defumado

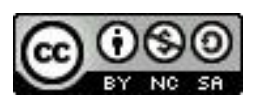


Os moradores avaliaram como ótimo o sabor dos peixes defumados. Assim, foram obtidas experiências junto à comunidade produtora de peixe sobre novas metodologias e a diversificação do processamento de peixe pode, sendo um fator positivo para o consumo interno, existindo a possibilidade de comercialização entre os pequenos produtores do assentamento. A boa aceitação de pescado defumado foi reportado para tilápia do Nilo (BIATO et al., 2005) e para jundiá (GONÇALVES e CEZARINI, 2008).

Destaca-se que as ações de extensão de cunho social e treinamento foram realizados com êxito dentro do assentamento Itamaraty, interagindo o ensino a pesquisa e a extensão de forma harmônica. Existe a necessidade de realização destas ações de transferência de conhecimento no meio acadêmico, sendo repassado o conhecimento obtido na universidade para o meio social (GABRIEL et al., 2015).

Para a comunidade que recebeu o treinamento, adotou-se medidas profiláticas durantes o processamento dos peixes para evitar contaminações, utilizando informações técnicas, visando garantir a qualidade do produto elaborado. O trabalho promoveu a capacitação de recursos humanos para realização da atividade do dia de campo na unidade de beneficiamento, sendo observado uma disseminação do conhecimento entre os moradores do assentamento. Nesse aspecto os alunos das UFGD contribuem com o acesso a informações, sendo repassada a comunidade local por meio de treinamento realizado na unidade de beneficiamento de carne da UFGD,

\section{CONCLUSÃO}

A técnica foi bem aceita pela comunidade que demonstrou interesse no processamento de produtos da pesca. Deste modo, a defumação é uma técnica que pode aumentar o consumo do pescado pelo mercado consumidor.

Esta ação de extensão além de fazer a difusão do conhecimento, foi de fundamental importância para integração da comunidade acadêmica com o sistema produtivo e os apreciadores de pesca artesanal.

\section{REFERÊNCIAS}

ADEYEYE, S.; O. OYEWOLE. An Overview of Traditional Fish Smoking In Africa. Journal of Culinary Science \& Technology, v. 14, n. 3, p. 198-215, 2016. 
ASSIS, M. F.; FRANCO, M. L. R. S.; STÉFANI, M. V.; FRANCO, N. P.; GODOY, L. C.; OLIVEIRA, A. C.; VISENTAINER, J. V.; SILVA, A. F.; HOCH, A. L. V. Efeito do alecrim na defumação da carne de rã (Rana catesbeiana): características sensoriais, composição e rendimento. Ciênc. Tecnol. Aliment. v.29 n.3 Campinas July/Sept. 2009. http://dx.doi.org/10.1590/S0101-20612009000300016

BIATO, D. O. Detectação e controle de off-flavor em tilápias do Nilo, por meio de depuração e defumação. Tese de mestrado em Ciências e Tecnologia de Alimentos, Piracicaba: Escola Superior de Agricultura ñLuiz de Queirozò, Universidade de São Paulo, 2005.

FRANCO, M. L. R. D. S., VIEGAS, E. M. M.; KRONKA, S. N.; VIDOTTI, R. M.; ASSANO, M.; GASPARINO, E. Effects of hot and cold smoking processes on organoleptic properties, yield and composition of matrinxa fillet. Revista Brasileira de Zootecnia, v. 39, n.4, p. 695-700, 2010.

GABRIEL, A. M. A.; SOUZA, R. DE.; OLIVEIRA, E. R.; ROSSINI, L. C.; MONÇÃO, F. P.; RAMOS, M. B. M.; GIMENES, L. S.; PEREIRA, T. L.; SILVA, E. C. P. Orientação em apiários no assentamento amparo, Dourados-MS. Edição especial SEREX, v.2. n.3, 2015.

GEORGE, F.; A. OGBOLU, O. OLAOYE, S. OBASA, A. IDOWU AND D. ODULATE. Fish processing technologies in Nigeria: a case study of Ibeju-Lekki local government area, Lagos State. Am. J. Food. Technol. v. 9, n. 6, p. 302-310, 2014.

GONÇALVES, A. A.; CEZARINI, R. Agregando valor ao pescado de água doce: defumação de filés de jundiá (Rhamdia quelen) adding value to freshwater fish: smoking fillets of jundiá. Rev. Bras. Enga. Pesca, v.3, n. 2, jul. 2008.

GUIMARÃES, L.; SANTOS, A. C. D.; FERREIRA, E.; PEREIRA, D.; F. COSTA. Microbiological quality of trahira fish (Hoplias malabaricus) from Baixada Maranhense, municipality of São Bento-MA. Arquivos do Instituto Biológico, v. 84, 2017.

LOZANO, I., S. LLAMAZARES VEGH, A. DOMÁNICO AND A. ESPINACH ROS. Comparison of scale and otolith age readings for trahira, Hoplias malabaricus (Bloch, 1794), from Paraná River, Argentina." Journal of Applied Ichthyology, v. 30, n.1, p. 130-134, 2014.

MENDES, G. A.; ROCHA JÚNIOR, V. R.; RUAS, J. R. M.; VIEIRA E SILVA, F.; CALDEIRA, L. A.; PEREIRA, M. E. G.; SOARES, F. D. S.; PIRES, D. A. A. Características de carcaça e qualidade da carne de novilhas alimentadas com silagem de capim-marandu. Pesq. agropec. bras, v.47, n.12, Brasília, Dec. 2012. http://dx.doi.org/10.1590/S0100-204X2012001200014

PAZIANOTO, L. H.; CIONEK, V. D. M.; FOGAÇA, F. N.; BENEDITO, E. Feeding and body condition of an invasive fish species under different environmental conditions. Neotropical Ichthyology, v. 14, n. 1, 2016. 
PIRES, D. R.; JAMAS, A. L. A.; AMORIM, E.; AZEVEDO-MELEIRO, C. H. D.; SILVA, P. P. D. O; OLIVEIRA, G. M. D. Chemical characterization of marine fish of low-commercial value and development of fish burgers. Pesquisa Agropecuária Brasileira, v. 52, n. 11, p. 1091-1098, 2017.

REIS, T.; SANTOS, H.; BARBOSA, S.; PEIXOTO, T.; MARUO, V.; PAIVA, F.; M. SATO. Hoplias aff. malabaricus Bloch, 1794 (Characiformes: Erythrinidae) parasites. Arquivos do Instituto Biológico, v. 84. 2017.

SOUZA, M. L. R.; VIEGAS, E. M. M.; SOBRAL, P. J. A ; KRONKA, S. N. Efeito do peso de tilápia do Nilo (Oreochromis niloticus) sobre o rendimento e a qualidade de seus filés defumados com e sem pele. Ciência e Tecnologia de Alimentos, v. 25, n. 1, 2005.

SOUZA, M. L. R.; BACCARIN, A. E.; VIEGAS, E. M. M.; KRONKA, S. N. Defumação da tilápia do Nilo (Oreochromis niloticus) inteira eviscerada e filé: aspectos referentes às características organolépticas, composição centesimal e perdas ocorridas no processamento. Revista Brasileira de Zootecnia, p. 27-36. 2004.

VIDAL, L.V.O.; XAVIER, T. O.; MOURA, L. B.; MICHELATO, M.; MARTINS, E. N.; FURUYA, W. M. Apparent digestibility of wheat and coproducts in extruded diets for the Nile tilapia, Oreochromis niloticus. Revista Brasileira de Saúde e Produção Animal, v. 18, n. 3, p. 479-491, 2017.

VOLCAN, M. V.; LANÉS, L. E. K.; GONÇALVES, Â. C.; FONSECA, A. P.; CIRNE, M. P. The fish fauna of the Corrientes stream basin, Patos lagoon system, state of Rio Grande do Sul, southern Brazil." Check List, v. 8, n. 1, p. 077-082, 2012.

MORAIS, C.; MACHADO, T. M.; TAVARES, M.; TAKEMOTO, E.; YABIKU, H. Y. \& MARTINS, M. Defumação líquida da truta arco-íris (Onchorhyncus mykis): Efeitos do processamento e da estocagem nas propriedades físicas, químicas e sensoriais. Revista do Instituto Adolfo Lutz, v. 56, n. 2, p. 43-48. 1996.

SOUZA, M. L. R.; BACCARIN, A. E.; VIEGAS, E. M. M.; KRONKA, S. N. Defumação da tilápia do nilo (Oreochromis niloticus) inteira eviscerada e filé: aspectos referentes às características organolépticas, composição centesimal e perdas ocorridas no processamento. Revista Brasileira de Zootecnia, v. 33, n. 1, p. 27-36. 2004. 